\title{
İkibinli Yıllarda Türk Oyun Yazarlığı
}

\author{
Selen KORAD BİRKIYYE* \\ İstanbul Devlet Tiyatrosu
}

\begin{abstract}
$\ddot{O}_{z e t}$
Bir ülkenin özgün tiyatro üslubundan söz etmek isteniyorsa yapılacak ilk şey, yazll tiyatro metinlerini gözden geçirmektir. Yazılı metin henüz tamamlanmamış bir tiyatro anlamını taşısa da, Antik Yunan'dan beri tiyatronun temel öğelerinden birisi olma özelliğini korumuştur. Dolaylslyla bir ülkenin tiyatrosunu anlayabilmek için, tiyatro metinleri inanılmaz ipuçları sağlarlar.

Bu bildirinin amacı, Türkiye'de darbe sonrası döneminin ardindan geçen sürecin ardından yeni milenyumun oyun yazarlı̆̆ına nasıl bir dönem açtığını saptamaktır. Bunu yapabilmek için 2000'li yıllarda Devlet Tiyatroları, IBŞT, Kocaeli ve Eskişehir Şehir Tiyatroları ile özel tiyatroların repertuvarlarına odaklanılacaktır. Ortaya çıkan portre, Türk toplumunun geçirdiği toplumsal ve politik dönüşümle de bağlantıll olarak, tiyatronun içinde bulunduğu durum üzerine bir fikir verecektir. Bu tanımlayıcı bir araştırma olacak, birincil ve ikincil verilerin yardımıyla bir literatür tarama çalışması yürütülecek, oyunların içerikleri analiz edilerek, dönem eğilimi karşılaştırması yapılacaktır. Cumhuriyet döneminin başlangıcından 1980'lerin sonuna kadar üzerinde önemle durulan bu konu, böylece yeni binyılın getirdiği verilerle -şu an için- tamamlanmış bir tarihsel çizgiye oturabilecektir.
\end{abstract}

Anahtar sözcükler: Oyun yazarlı̆̆l, tiyatro, temalar, türler

\begin{abstract}
The first step for evaluating the theatre of a country is looking for the scripts. Although scripts can be defined as an incomplete form of theatre, because the ultimate form is meeting with the audience on the stage, it is one of the basic components of the theatre from Ancient Greece. So scripts can give valuable materials for understanding of the theatre of a certain country.

The aim of this research is to evaluate the situation of playwrighting in Turkey in the new millennium. So the research question is "how can we define the direction of Turkish theatre in the last ten years?" In order to do this, repertoires of some subsidized and private theatre companies will be investigated. This research will show the situation of the theatre and playwrighting in Turkey. The research will be a descriptive one, primary and secondary data will be collected and a content analysis will be made on new plays in terms of the themes and styles. So related to the researches about the previous phases of Turkish theatre, the portrait of Republican Turkish drama will be updated.
\end{abstract}

Key words. Playrighting, drama, styles, themes.

*Dr.,Dramaturg, İstanbul Devlet Tiyatrosu, Eposta: koradbirkiye@yahoo.com 


\section{Amaç}

Yaşayan bir sanat formu olarak tiyatro, her zaman çağının aynası olmuştur. "Çağın ruhu"nun etkisini oyunlar üzerinde büyük ölçüde gösterdiğinden söz edilebilinir. Cumhuriyet dönemi Türk tiyatrosu ele alındığında da, oyunların değişen perspektiflerin, ideolojilerin ve mentalitelerin yansımalarının görüldüğü bir arenaya dönüştüğü gözlemlenmektedir. Daha önce yapılan çalışmalar, Türk tiyatrosunun yönelimini 1990'lara kadar getirmektedir (Ak1, 1968; And, 1983; Nutku 1985; Sav, 1984; Akınc1, 2003; Belkıs, 2003; Çelenk, 2003; Korad Birkiye,1996). Kabaca Cumhuriyet döneminin değişen sosyopolitik koşullarının tiyatroyla ilişkisinin yakınlığı bu çalışmalarda ortaya konulmuştur. Böylece Cumhuriyet'in ilk yıllarında yeni bir ulus yaratma ve toplumsal değişimin ortaya çıkarttığı soru işaretlerini ve bir ideoloji yaratma çabası ilk dönem oyunlarında gözlemlenmektedir ${ }^{1}$. 2. Dünya Savaşı sonrası ${ }^{2}$ yaşanan olumsuz koşullar ve tek parti iktidarı tiyatroda kendisini resmi ideolojinin yansımaları ve ahlakçı, romantik bir bakışla göstermiş, oyun üretimini azaltmıştır. 1950'lerle başlayan çok partili hayata geçiş ${ }^{3}$, görece eleştirel ve objektif oyunların yazılmasına vesile olmuştur. Bu dönem günümüze hala damgasını vuran tiyatro yazarlarından bazılarının da ilk eserlerini verdiği yıllardır, işlenen konular ve bakış açıları da çeşitlenmeye başlamıştır. 1961 anayasasının açtığı özgürlük dönemi ${ }^{4}$, Türk tiyatrosunun "altın çağı” olarak adlandırılmaktadır. Bu dönemde hem nitelik hem de nicelik açısından büyük bir gelişme gözlemlenmiş, sosyal ve ekonomik sorunlar, bilinçlenme ile birlikte oyun yazarlarının öncelikli gündemlerini işgal etmeye başlamış, tiyatroda yeni denemelere gidilmiştir. 1970'lere gelindiğinde ${ }^{5}$ ülkenin içinde bulunduğu ekonomik ve toplumsal kriz, tiyatroyu derinden etkilemiş, nitelik kaybı temel sorunlardan birisi haline gelmiştir. 12 Eylül askeri darbesi ${ }^{6}$ ise oyun yazarlığında bir dönüm noktası olmuştur. Toplumun pek çok alanı ve kurumunda olduğu gibi darbe, oyun yazarlığı alanında da büyük bir tahribata neden olmuştur. Bu travmanın atlatılabilmesi ve yeni bir yol çizilebilmesi için oldukça uzun bir zaman geçmesi gerekmiştir. Hala da bu tıkanıklığın aşıldığından söz etmek ve Türk tiyatrosunun altın yıllarını bir hayal olarak anımsamaktan öteye gidildiğini söylemek zordur.

$\mathrm{Bu}$ incelemenin çeşitli amaçları söz konusudur. Birincisi, tiyatroların yeni oyun yazarları hakkındaki repertuvar politikalarını saptamak; ikincisi, son on yıllık dönemde tercih edilen oyun yazarları, oyunlar, temalar ve türleri belirlemek; üçüncüsü de, çözüm yollarını aydınlatmaya çalışmaktır.

\footnotetext{
${ }^{1}$ İlk yılların göze çarpan yazarları: F.N. Çamlıbel, P. Safa, R.N. Güntekin, Y.K. Karaosmanoğlu, İ.H. Baltacıŏlu, H.R. Gürpınar, İ.H. Baltacıŏglu

${ }^{2}$ 1940-1950 dönemi yazarları: C.F.Başkut, A.K. Tecer, S.Simavi, N. Kurşunlu, S. Aksal

${ }^{3}$ 1950-1960 : O. Asena, T. Özakman, N. Cumalı, M.C. Anday, Ç. Altan, N. Kurşunlu

${ }^{4}$ 1960-1970: G. Dilmen, G. Sümer, B. Sabuncu, T. Oflazoğlu, V. Öngören, O. Arayıcı, R. Bilginer, C. Atay, Ü. Köksal, T. Buğra

${ }^{5}$ 1970-1980: E. Aytekin, B. Erenus, U. Mumcu, Y. Müderrisoğlu

${ }^{6}$ 1980-1999: Ü. Ayvaz, M. Baydur, M. Mungan, E. Gökgücü, Y. Pazarkaya
} 


\section{Yöntem}

Bir oyun metninin ancak sahnelendiği anda tamamlanacağı ve var olma sebebini yerine getireceği varsayımından yola çıkarak, bu incelemede ele alınacak oyunlar için profesyonel bir tiyatroda sahnelenmiş olma ilkesi belirlenmiştir. Hangi tiyatroların repertuvarlarının taranacağına ise "Yargıya Dayalı Örnekleme" türü benimsenerek karar verilmiştir. Buna göre, ödenekli tiyatrolar ile Türkiye'de sayısal olarak ve düzenli olarak en çok oyun oynadığı varsayılan konvansiyonel tiyatro çizgisini yürüten profesyonel özel tiyatrolardan "en tanınmışları" seçilmiştir. Buradaki en tanınmışlık kıstası, basın yayın organlarında en çok adı geçen ve tiyatro camiasında belli bir statüsü olan ve on yıl içinde düzenli prodüksiyon yapan tiyatrolar anlamında kullanılmaktadır. Böylece adı geçen sürede düzenli temsil veren ve her sene en az bir oyunla izleyiciyle buluşan İstanbul ve Ankara'da faaliyet gösteren 20 tiyatronun repertuvarı incelenmiştir. Böylece yaklaşık 1500 oyun taranmış ve bu taramanın tüm popülasyonun eğilimini temsil ettiği varsayılmıştır.

\section{Sinırlılıklar}

Ödenekli tiyatroların edebi/repertuvar kurullarından geçip repertuvar havuzuna kabul edilen, ama henüz sahnelenmemiş oyunlarla, kitap olarak yayınlanmış, ama izleyiciyle buluşmasını sahne üzerinde gerçekleştirmemiş oyunlar, bu değerlendirme içine alınmamıştır. Doğal olarak yazılan yeni oyun sayısı burada incelenenlerin kat be kat üzerindedir. Yalnız DT repertuvar havuzuna kabul edilmiş oyun sayıs1 3000 civarındadır ve bunlardan sadece $\% 25$ 'i bu güne kadar sahnelenme imkanı bulmuştur. Ancak varsayımımız dahilinde, sahnelenmeyen oyunlar, yayınlanmış dahi olsa ve niteliği ne düzeyde olursa olsun, değerlendirme dışında bırakılmıştır. Ayrıca çocuk oyunlarından sadece repertuvar içindeki oranı şeklinde bahsedilmiş ve incelemeye alınmamıştır. Konvansiyonel çizgide tiyatro yapan topluluklar incelenmiş, avant-garde, yarı profesyonel, üniversite, amatör, ticari ve stand up/one man show olarak adlandırılanlar değerlendirme dışı bırakılmışlardır.

\section{Tiyatroların Repertuvarlarında Yeni Yerli Oyunlara Yer Verme Sıklığı}

Ödenekli tiyatroların repertuarlarında yer verdikleri yeni yerli oyunların oranlarına bakıldığında şöyle bir tabloyla karşılaşılmaktadır:

1999-2008 arasında Devlet Tiyatroları'nın on iki bölgesinde her yıl sergilenen oyun sayısı, yılda ortalama 122 oyundur. Bu oyunların içinde yerli/telif eser, yabancı ve çocuk oyunu olarak farklı oranlar mevcuttur. Çocuk oyunları çıkartıldıktan sonra DT repertuarının ortalama yarısı yerli, yarısı da yabancı oyunlardan oluşmaktadır. Son yıllarda bu sayıyı yerli oyunlar lehine \%70 gibi bir orana çekme çabası varsa da, pratik buna çok izin vermemektedir. Bu pratik sorunların neler olduğuna incelemenin sonunda değinilecektir. Sonuç olarak bir sezon içinde ortalama 45 yerli oyun DT sahnelerine çıkmaktadır. Ancak bu oyunlar arasında 1990'ların sonlarında ve ikibinli yıllarda yazılmış oyunların oranına baktığımızda, yeni oyun yazarlığına dair ilginç bir tablo ile karşılaşmaktayız. Rastgele örneklemeyle seçilen 2006-2007 sezonunda oynanan toplam 131 oyun içinde sadece 7 yeni 
yerli oyun göze çarpmaktadır. On yıl içinde en az yeni oyun oynanma oranı, 6 yeni oyun ile 20042005 sezonuna, en fazla yeni oyun ise 16 yeni oyunla 2001-2002 sezonuna aittir. Ancak bu yeni telif eserlerin hepsinin orijinal ve gerçekten yeni oyunlar olduğunu öne sürmek mümkün değildir. Bunlardan bazıları bir arkeoloji çalışmasıyla gündeme gelen kimi eski oyunlar ve edebiyat uyarlamaları ile DT' de daha önce hiç sahnelenmemiş, ama başka tiyatrolarda izleyiciyle buluşmuş oyunlardır. 2001-2002 sezonunda sahnelenen 16 yerli oyundan uyarlamalar1, yeni ve özgün olmayan eserleri çıkarttığımızda geriye 6 yeni oyun kalmaktadır. Öte yandan DT'nin yeni yerli oyunlara yer verme oranları ilden ile bölgeden bölgeye de farklılık göstermektedir. Sanatsal rekabetin fazla olduğu, izleyicinin pek çok farklı alternatife ulaştığı İstanbul'da, İstanbul Devlet Tiyatrosu repertuvarında yerli ve yabancı yeni oyunlara ve edebiyat uyarlamalarına diğer illerden daha fazla yer verilmektedir. Metropoller dışında, özellikle orta, doğu ve güneydoğu Anadolu'daki DT’lerde ise daha çok yerli klasikleşmiş oyunlar tercih edilmektedir.

İstanbul Belediyesi Şehir Tiyatroları 1999-2008 yılları arasında sezon başına ortalama 11 yeni oyunla perdelerini açmaktadır. Bunların arasındaki yerli, yabancı oyun dengesi sezondan sezona değişmektedir. 10 yıllık dönem içinde, sergilenen toplam 109 oyundan 54'ü yerlidir. Ancak İBŞT'nin repertuvar politikasında genel bir tutarlılıktan söz etmek şu açıdan güçtür ki, kimi sezonlarda yerli oyun oranı \%100'e yakınken, kimi sezon yabancı oyunların ağırlığı \%85'tir. Sergilenen yerli oyunlar arasında yeni yazar ve yeni oyunlara yer verme oranı ise oldukça düşüktür. Örneğin 2002-2003 tiyatro sezonunda oyunların tümü yerli eserdir. Ancak bunların tümü de bir çok defa sahnelenmiş klasikleşmiş adını verdiğimiz telif eserlerdir ${ }^{7} .10$ senelik dönem içinde, uyarlamaları saymazsak İBŞT repertuvarında sahnelenen yeni yazılmış oyun sayısı altıdır ${ }^{8}$. Bu verilere dayanarak İBŞT’nin politikasını çoğunlukla sağlamcı, denenmiş, riski az yerli oyunların tercih edildiği bir repertuvar olarak değerlendirmek yanlış olmaz.

Bakırköy Şehir Tiyatrosu, Kocaeli Şehir Tiyatrosu ve Eskişehir Belediye Tiyatrosu'nda ise durum kısaca şöyle özetlenebilir:

Bakırköy Şehir Tiyatrosu'nda kurulduğu günden bu güne dek sahnelenen 74 oyun içinde sadece 1 ' ${ }^{9}{ }^{9}$ yeni yazar/yeni metin kapsamına girmektedir. Kalanlar bilinen yerli yazarların tanınmış eserleri, çocuk oyunları ve yabancı(25) oyunlardır.

Türkiye'nin 3. Ödenekli şehir tiyatrosu olan Kocaeli Şehir Tiyatrosu, dünya tiyatro edebiyatının seçme eserlerinin sahnelendiği bir repertuvardan, son dönemlerde suya sabuna dokunmayan iddiasız yapitlara doğru bir dönüşüm geçirmiştir. Repertuvar istatistiklerine gelince durum şöyle özetlenebilir: 1999-2008 yılları arasında toplam 43 oyun sahnelenmiştir. Bu oyunların 12'si çocuk oyunudur.

\footnotetext{
${ }^{7}$ Bu oyunlar şunlardır: Bir Adam Yaratmak; Ocak; Ya Devlet Başa Ya Kuzgun Leșe; Seferi Ramazan Beyin Nafile Dünyası, Aşk-1 Memnu, Yağmur Sıkıntısı, Düğ̈n ya da Davul, Sersem Kocanın Kurnaz Karısı, Meraki.

${ }^{8}$ Bu oyunlar: Sokağa Çıkma Yasağı, Barıșa Șans Verin, Gayrı Resmi Hürrem, Gılgameș(Z. Avcı), Kantocu, Leyla ile Mecnun (İ. Pala)

${ }^{9}$ Bu Özen Yula’nın Gözü Kara Alaturka adlı eseridir. Eğer Muzaffer İzgü'nün oyunlarını da yeni metin kapsamına sokacak olursak bu sayıyı 3'e çıkartabiliriz.
} 
Kalanlardan 16'sı yerli, 18'i yabancı eserdir. Yerli eserler içindeki seçimlere baktığımızda, özel proje olarak üretilen Açık Tiyatro etkinlikleri dışındakiler arasında Özen Yula (Kırmızı Yorgunları) ve Behiç $\operatorname{Ak}(\underline{\text { Ayrılık}})$ dışında yeni oyun yazarı ve esere rastlanmamaktadır. Bunun tek istisnası Uluslarası Tiyatro Festivali için hazırlanan ve bu sezon da oynanan Emre Koyuncuoğlu uyarlaması Uygur edebiyatının fal kitabı Irk Bitig, yani “İyi Gelecek Kitabı”dır. Kalanlar, Turgut Özakman, Melih Cevdet Anday, Memet Baydur, Muzaffer İzgü gibi orta yaş ve yaşli jenerasyonun ustalarından seçilmiş oyunlardır.

Eskişehir Şehir Tiyatrosu kurulduğu tarih olan 2000 yılından beri çocuk oyunları dahil toplam 37 oyun sahnelemiştir. Sahnelenen 25 büyük oyununun 17'si yerlidir. Repertuvar seçiminde ise eskiler ağırlıkta olmakla birlikte 6 yeni yerli oyuna ${ }^{10}$ da yer verilmektedir. Ancak yeni oyun seçkisinde komedi ve müzikal ağırlıklı bir eğilim sezilirken, diğer oyunlarda ise geniş bir yelpaze gözetilmektedir. Yeni oyunlarda yine risksiz prodüksiyonlar ve yazarlar tercih edilmektedir.

Özel tiyatrolara baktığımızda ise şöyle bir resim ile karşılaşmaktayız ${ }^{11}$ :

Tiyatro İstanbul ${ }^{12}$, Tiyatro Kare ${ }^{13}$, Oyun Atölyesi ${ }^{14}$, Aksanat Prodüksiyon Tiyatrosu ${ }^{15}$ 'nun repertuvarlarında yerli oyun seçimi oldukça düşüktür. Adı geçen tiyatroların on yıllık repertuvarında yerli oyun sayısı en fazla bir ya da ikidir. Ancak bu seçilen az sayıdaki yerli oyunda tercih yeni bakışlar, yeni teatral eğilimler gösteren genç, yerli yazarlardan yana kullanılmıştır. Tiyatro Stüdyosu ise hiç yerli oyun oynamamıştır.

Tiyatro Oyunevi de aynı mantık içinde farklı duruşlar sergileyen yeni oyunlar ya da oyunlaştırmaları repertuvarına almakta ve yukarıda adı geçen tiyatrolara oranla, oldukça yüksek bir sayıda yeni yerli proje gerçekleştirmektedir. Murat Uyurkulak'ın TOL'ü, Nihat Genç'in Gavara'sı, Hasan Ali Toptaş'ın şiirlerinden oluşan Yalnızlıklar'ı bu seçimin yansımalarıdır. Çocuk oyunları dahil 13 projeye imza atan Tiyatro Oyunevi, Sartre'dan Genet'ye, Sofokles'ten Lorca'ya uzanan bir çizgide repertuvar hazırlamaktadır.

Geçtiğimiz günlerde kaybettiğimiz sanatçı Hadi Çaman'ın tiyatrosu Yedi Tepe Oyuncuları repertuvarında, yabancı oyunlara ağırlık verilmiştir. Yerli oyunlarda tercih, yeni yazarların yeni eserlerindense, tanınmış, bilindik yerli yazarların yeni ve eski oyunlarından yana olmuştur.

\footnotetext{
${ }^{10} \mathrm{Bu}$ oyunlar, Haldun Dormen'in yazıp yönettiği, Kantocu ve Nerede Kalmıștık, Özen Yula, Gözü Kara Alaturka, Behiç Ak, Ayrılık; Hasan Erkek, Don Kişot'un Ruhu ve anonim bir çalışma olan Gülme Komşuna'dır.

${ }^{11}$ Ferhan Şensoy ve Ortaoyuncular, Şensoy’un kendi yazdığı oyunların temel alındığı bir çizgi sürdürdükleri için bu değerlendirmeye alınmamıştır. BKM oyuncuları da ağırlıklı olarak kendi üretimleri olan oyunların sahnelendiği bir şov tiyatrosu olarak değerlendirme dışında bırakılmıştır. Stüdyo Oyuncuları ve Kumpanya ise konvansiyonel tiyatro anlayışından çok, deneysel bir çizgi sürdürdükleri için kapsam dışındadırlar. DOT ise henüz çok yeni bir tiyatro olduğundan 10 yıllık bir süre için anlamlı veri sağlayamayacağ 1 için dışarıda birakılmıştır.

${ }^{12}$ Kurulduğu yıldan beri 25 oyun sahneleyen tiyatronun repertuvarındaki tek yerli oyun Refik Erduran'in Seher Vakti'dir.

${ }^{13}$ Söz konusu tarihler arasında Tuncer Cücenoğlu'nun Neyzen ve Burak Akkul'un yazdığ 12 Oda 1 Sinan adlı tv skecinin sahneye uyarlaması ile Hayatımın Oyunu adlı tek kişilik gösteri sahnelen yerli oyunlardır.

${ }^{14}$ Kurulduğu yıldan beri yerli oyun olarak sadece Turgay Nar'ın Çöplük adlı oyunu yer almıştır.

${ }^{15}$ Sevilmek, Bilge Karasu; Tek Kișilik Șehir, Behiç Ak
} 
Tiyatro Pera, repertuvarını geniş bir yelpazede tutmaya çalışan, Shakespeare klasiklerinin yorumlanmasında olduğu kadar, yeni oyun seçiminde de farklı ve eleştirel bir bakış getirmeye çalışan bir tiyatrodur. Bu tiyatronun yerli oyun seçimindeki itici güç, sanat yönetmeni Nesrin Kazankaya'nın yazdığı yeni metinlerdir. 2 çocuk oyunu da sahneleyen Tiyatro Pera'nın kurulduğu yıl olan 2002'den bu yana sergilediği toplam oyun sayısı, 11, yabancı yerli oyun oranı ise, 5 yabancı oyuna karşın, 4 yerli oyundur.

Bu yıl 10. Kuruluş yıldönümünü kutlayan Semaver Kumpanya, geçen sürede çocuk oyunları dahil 12 oyuna imza atmıştır. Orhan Kemal'in romanından uyarlanan Murtaza; Max Frisch'in Bay

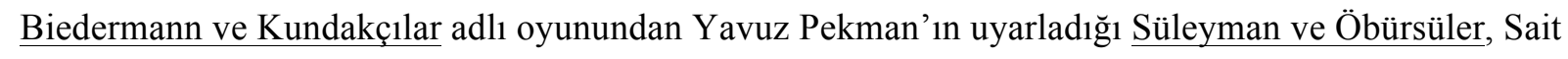
Faik'in eserinden uyarlanan Semaver Kumpanya , topluluğun repertuvar ilkesini "sözü olan" ya da edebi değeri bulunan eserlerden yana göstermektedir. Trainspotting, Chamaco, İnfazc1 gibi ülkemizde daha önce sahnelenmemiş yabancı oyunlara da yer veren tiyatronun yerli oyun tercihleri, daha çok dünya görüşlerini yansıtan uyarlamalarla şekillenmektedir.

Sadri Alışık Tiyatrosu ilk yıllarındaki yabancı oyun ağılıklı repertuvar seçimini, yeni yerli oyunlar lehine değiştirmiştir. Ancak oyunların çizgisi kaliteli, farklı, ses getiren yerli oyun seçimlerinden, son yıllarda bulvar komedilerine, popüler hafif komedilere doğru kaymıştır. Atıf Yılmaz, Çetin Akcan, Kandemir Konduk, Metin Kaçan, Huri Aykut, Doğuş Elden ${ }^{16}$ yerli oyun seçiminde tercih ettikleri yazarlardır.

Tiyatro Kedi kuruluşundan itibaren 15 prodüksiyona imza atmıştır. Görece ticari ve müzikal oyun seçimleriyle göze çarpan tiyatronun repertuvarında Tiyatro Kılçık'la yapılan iki kabare dışında sadece bir yerli eser sahnelenmiştir. Bu da Tarık Günersel'in yazdığı yarı belgesel çağrışımlı Yarım Bardak

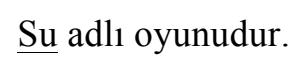

Tiyatro Ayna'nın sanat yönetmeni Dilek Türker'in oyun seçimleri, Latife, Kuvay-1 Milliye Kadınları gibi genelde tek kişilik, yerli, vatanseverlik temalı ve Cumhuriyet ideolojisini destekleyen, 1smarlama oyunlar olarak ortaya çıkmaktadır. Bu repertuvar anlayışı 90'lardan beri devam etmiş ve genelde tanınmış yazarların yazdıkları oyunlar üzerinden şekillenmiştir. Ancak, geçtiğimiz sezon Önder Paker'in yazdığı karısını aldatan koca temalı Var mısın? adlı müzikli bir komedi ile tarz değiştirmiştir.

Kent Oyuncuları'nda, DT ekolünden gelen Yıldız ve Müşfik Kenter, benzer bir anlayışta bir repertuvar ilkesini uygulamaktadır. Kurulduğu 1960 sezonundan bu yana dünya tiyatro edebiyatının çağdaş ve klasik oyunlarına yer veren Kent Oyuncuları'nın repertuvarı yerli oyunları bünyesinde barındırmakla birlikte, bu oran özellikle 2000'li yıllardan itibaren kayda değer bir ağırlık oluşturmamaktadır. 1999-2008 arasında toplam dört yerli oyunla izleyici karşısına çıkan Kent Oyuncuları'nın aynı dönemde sahneledikleri toplam oyun sayısı 19'dur. Bu yerli oyunlar Ben Anadolu

\footnotetext{
${ }^{16}$ Ağır Roman, Metin Kaçan; Tanrım, Huri Aykut; Yeni bi'șiy, Show Theatre Anonim; Güllü, Atıf Yılmaz; Bu Așkta Bi Șey Var, Çetin Akcan; Telekolik, Doğuş Elden; Çapraz Așklar, Kandemir Konduk.
} 
dışında ilk defa sahnelenmekle birlikte, hepsinin ortak özelliği Yıldız veya Müşfik Kenter'in oynadığı tek kişilik oyunlar olmasıdır. ${ }^{17}$

Dostlar Tiyatrosu, politik duruşunu 2000'li yıllarda da sürdürmeye çalışmıştır. 1999'dan bu yana 10 oyun sahneleyen tiyatroda, uyarlamaları da sayarsak yerli oyunların toplam sayıs 5 'tir. Politik tiyatronun gündemi takip etme derdiyle de örtüşecek bu uyarlamalar Genco Erkal'ın kendisi tarafindan yapılmıştır. Deprem korkusunu işleyen Behiç Ak'ın Fay Hattı dışında Erkal'ım uyarladıkları, kaybettiğimiz büyük şair Can Yücel'in konu edildiği Can, savaş rüzgarlarının estiği günlerde sahnelenen Yaşasın Savaș, irticanın önlenemeyen yükselişine dikkat çeken Aymazoğlu ve Kundakçılar, Sivas katliamının işlendiği Sivas 93'dür.

Ankara Sanat Tiyatrosu (AST) da benzer bir çizgi içindedir. On yılda çocuk oyunları dahil 36 oyun sahnelenmiştir. Sezon repertuvarlarının yaklaşık \%60’ı çocuk oyunlarından oluşmaktadır. Toplam 7 yerli oyun izleyiciyle buluşmuştur. Bunlar arasında Metin Balay'ın yazdığı toplumsal eleştirisi güçlü metinler ve Nazım Hikmet uyarlamaları ağırlıktadır. ${ }^{18}$

1989'dan beri tutarlı bir çizgide yerli oyunlar oynayan Ankara Ekin Tiyatrosu on y1llık sürede 11 yerli prodüksiyona imza atmıştır. Oyun seçimleri çoğunlukla Güngör Dilmen, Aziz Nesin, Tuncer Cücenoğlu gibi tanınmış yerli yazarlar ile tiyatronun kurucusu Faruk Güvenç ve Semih Çelenk'in kaleme aldıkları oyunlardan oluşmaktadır. Sahnelenen oyunların sekizi yeni olarak değerlendirilebilir. Bu bağlamda bakıldığında incelediğimiz tiyatrolar içinde bilinçli olarak yerli oyun grafiğini sürdüren ve bunu oyun çizgisinden çok ödün vermeden yapan tek topluluk gibi gözükmektedir.

\section{Oyunları En Çok Sahnelenen Yazarlar}

$\mathrm{Bu}$ on yıllık dönemde en çok oyunu oynanan yazarlara bakıldı̆̆ında durum şudur:

Refik Erduran 1950-60’larda başlayan oyun yazma macerasını tüm hızıyla sürdürmektedir. Hemen hemen her sezon en az bir yeni oyunu DT sahnelerinde boy göstermiştir. Oyunlarında popüler konu ve tartışmaları, yüzeysel bir aksiyon çizgisi içinde kimi zaman komediyle harmanlanarak, gazete makalesi tonunda toplumsal eleştiriler eşliğinde yazmıştır. Oyunları, Kent Oyuncuları, Hadi Çaman ve Yedi Tepe Oyuncuları gibi özel topluluklar tarafından da 90'lı yılların sonları ve ikibinli yılların başlarında da sahnelenmiştir. Erduran'ın bu dönemde sahnelenen oyunlarına göz atılacak olursa , Bordello adlı oyununda, Bordello adlı bir randevu evinde, ve yolsuzluklar ve faili meçhul cinayetlerin kol gezdiği bir ülkede, örgüt üyesi Gür ile kardeşinin değiş̧en dünya düzeninin ardından değiş̧en yaşamları anlatılır. Yemenimin Uçları'nda, psikolojik buhran geçiren Zehra'nın hayatını sorgulaması,

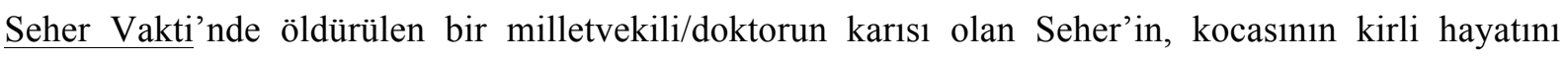
keşfetmesi ve cinayeti aydınlatması; Bahçemdeki Ayı'da, zorbalığa baş kaldıran manik depresif, eğitimli bir kadının eğlenceli öyküsü anlatılır. Direkler Arasında'da, gökten inen Cemile'nin, yüzyıl

\footnotetext{
${ }^{17}$ Hep Așk Vardı, Yıldız Kenter; Huysuz İhtiyar, Oğuz Aral; Nasreddin Hoca Bir Gün, Sönmez Atasoy; Ben Anadolu, Güngör Dilmen.

${ }^{18}$ Metin Balay’ın oyunları: Yobaz, İnadına İnsan, Deniz Diye Bir Delikanlı, Nazım Hikmet: Yolcu ve Memleketimden İnsan Manzaraları; Behiç Ak, Ayrılık; Turgut Özakman, Töre.
} 
başı İstanbul'unda delikanlılığın, kabadayılığın ve namus bekçiliğinin ön planda olduğu bir çevrede, başına gelenler üzerine kuruludur. Erkeklerin etrafinda pervane olduğu Cemile, aslında onların içyüzünü açıklayarak foyalarını meydana çıkartmaya çalışsa da kurban kendisi olur.

Tuncer Cücenoğlu da yazarlık yaşamını uzun yıllardır sürdüren ve pek çok tiyatro tarafından oyunları tercih edilen bir yazardır. 2000li yıllar Cücenoğlu'nun yurtdışında pek çok ülkede oyunlarının sahnelenmesi açısında da önemlidir. Asker ocağında kaybedilen bir şapkanın aranma macerası Șapka'da, en büyük korkunun çığ düşmesi olduğu bir yerde, yeni bir insanın dünyaya gelmesi uğruna göze alınan çığ tehlikesi Çı̆̆'da, sevdiği kız uğruna sınanan Selim ve peşinden nehrin öteki yakasına geçenler Kızılırmak'ta, Neyzen Tevfik'in yaşamı Neyzen'de işlenmektedir. Ayrıca Cücenoğlu'nun milenyumdan önce yazdığı Kadıncıklar, Helikopter gibi eserleri hala popülerliklerini sürdürmektedir

Behiç Ak 90'lı yıllarda ilk oyunlarını yazmaya başlayan, ama patlamasını 2000'li yıllarda gerçekleştiren bir yazardır. Yazdığı absürd çağrışımlı oyunlarında yabancılaşmış ilişkiler, yan yana olup, birlikte olamama, modern çağın insana dayattıkları üzerinde durmaktadır. 1999'daki depremlerin ardından yazdığ Fay Hattı, bu eğilim içinde gerçekçilik ögeleri en ağır basan oyunlarından birisidir. Tek Kișilik Șehir adlı oyunu, internet vasıtasıyla kendilerine bir dünya ve kimlik yaratan insanların, gerçek ilişkilerdeki acemilikleri ve yabancılıkları başarıyla aktarılmaktadır. Ayrılık' da boşandıktan 13 sene sonra bir araya gelen bir kadın ve erkeğin, yeni insan olma yolundaki mücadeleleri eğlenceli bir dille anlatılmaktadır. Bu oyun 2000'li yılların en çok sahnelenen oyunlarından birisidir. Hemen hemen tüm ödenekli tiyatrolar ve kimi özel tiyatrolar tarafından repertuvara almıştır.

Özen Yula özellikle ödenekli tiyatroların en çok tercih ettiği yeni yazarların başında gelmektedir. Gözü Kara Alaturka'da İstanbul'da Harbiye'de işlenen bir cinayet, Gayri Resmi Hürrem'de Hürrem Sultan'ın iktidar hırsı ve aşkla yoğrulan yaşamı, Așk Evlerden Uzak’ta, günümüz metropollerinde yaşanan konfor içinde kaybolan aşkların, aynı daireyi kiralayan üç çiftin öyküleri düzleminde serimlenmesi, Kırmızı Yorgunları'nda ise kendilerine çizgi roman kahramanlarının isimlerini veren ayrıksı kahramanların şiddetle sonlanan öyküleri anlatılmaktadır. Yula'nın ilk oyunlarından Dünyanın Ortasında Bir Yer adlı tragedya ve kadın erkek ilişkileri, bir seri katil ve çocuk tacizi üzerine yazılan Ay Tedirginliği 2000'li yıllarda da izleyiciyle buluşmuştur.

Turgay Nar, Çöplük adlı oyunuyla gösterdiği tüyler ürpertici fantezisini, sonraları tarihi ve mistik konulara yöneltmiştir, Güz Bitiminde Moliere'de bir Kibarlık Budalası uyarlamasına girişmiş, Can Ateșinde Kanatlar'da Mevlana’yı, Hitit Güneși’nde kralın kör ettiği yontucunun görmeden güneş yontusunu yapmasını, Divane Ağaç’ta Yunus Emre'yi işlemiştir. Bu oyunların bir kısmı 9011 yılların ikinci yarısında yazılsalar da, izleyiciyle buluşmaları odaklandığımız döneme denk gelmiştir.

Civan Canova, 90'lı yıllarda sesini ilk defa Kıyamet Suları'nda ile duyuran bir oyun yazarı/oyuncudur. Son on senelik periodda bir sayım günü sokağa çıkamayan otel müşterilerinin geçirdikleri bir günü ironik bir dille anlattığı Sokağa Çıkma Yasağı, aydın bir adama aşık olup evlenen genç bir kadının monoloğu şeklindeki Düğün Şarkısı, internet çağının yalnızlaşmış ilişkileri üzerine 
kurulu Ful Yaprakları, farklı mekanlardaki erkekler tuvaletinde geçen, erkek dünyasına absürd bir bakış taşıyan Erkekler Tuvaleti yazarın en çok sahnelenen oyunlarıdır. Canova keskin gözlemi, duyarlı öyküleri ve dramatik yapıya hakimiyeti ile oldukça önemli eserler vermiştir. Son zamanlarda ise oyunlarının absürd, fantastik izleğini artırarak yeni denemelere girişmektedir.

Raşit Çelikezer de son yıllarda tanınmaya başlayan bir yazardır. Olay kurgusunu daha çok iç aksiyona dayandıran, dialoğa büyük ölçüde yüklenen oyunlar yazmaktadır. Bir otoparkın gizli bölümünde kısılıp kalan bir adam, peşinde tetikçiler ve yeni dünya düzeninin işlendiği Otopark Cinayetleri, çok para kazanmak için bütün insani değerleri çiğnemeye hazır olan yeni dünya düzeni gençlerinin anlatıldığı Hiçbir Şey, aydın bir erkekle bir kadın arasındaki ilişkiyi bir evliliğin kriz noktalarına odaklanarak anlatan Bavul Hikayesi, her gün aynı saatte parkta buluşup havadan sudan konuşan, ama en önemlisi kimsesizliklerini ve unutulmuşluklarını paylaşan iki yaşlı adamın anlatıldığı Bir Kușluk Vakti yazarın sahnelenen oyunları arasındadır.

Hasan Öztürk yaşı pek genç olmasa da, özellikle 1990’ların sonlarında ve 2000'li yılların başında pek çok oyuna imza atmış bir yazardır. Oyunları çoğunlukla absürd çağrışımlar içerir. Kurguladı̆̆ karakterlerin isimleri hiçbir çağrışım yapmayan saçma isimlerdir. Konu seçimleri günümüz dünyasının metaforu üzerine kurgulanmıştır. Tek mitolojik oyunu Tanrılar Erkek Olunca'da, sevgilisi Attis'in ölümüne sebep olan Kibele’nin Frig illerinden ayrılması ve Artemis ile verdiği tanrıçalık mücadelesini konu etmiştir. Konuk'da herkesin Mesih’i beklediği bir yılbaşı gecesi barda kumar oynayan Patron, Garson, Kız ve hayatlarının kumarını oynayan kitleler konu edilir. Avcı, ruhsal sorunları nedeniyle emekliye sevk edilen sorgucu polis Zum'un, karısı denetiminde tedavi amaçlı yaptığı hayali sorgulamalar üzerine kuruludur. Ancak müzisyen Gam'ın geçmiş olsun ziyaretine gelmesi ilişkiler düzlemini bir daha geri dönmemek üzere değiştirir.

Coşkun Irmak, pek çok çağdaşından farklı olarak hem toplumsal duyarlılığı ve eleştirisi güçlü oyunlar yazan, hem de konu seçiminde geniş bir yelpaze oluşturan bir yazardır. Yazdığı oyunların çoğunluğu henüz sahnelenmemiş olsa da, sahnelenenler arasında ilginç oyunlar göze çarpmaktadır. Siyah Çoraplılar'da Abdülhamit'in zulmüne uğrayan ilk Türk futbol takımının yıllar sonra Kuvay-1 Milliye ruhunun öncüsü olarak hürriyet rüzgarları estirmesini konu etmiştir. Miletos Güzeli'nde Terentius'un Andros Güzeli'nin bir uyarlamasını yapmıştır. Memurin Faslı’nda çağdaş bir orta oyunu formatında günümüzde memurların çektiği sıkıntıları gösteren 8 küçük öykü olarak kaleme almıştır. 50 Metre Yüksekten İçi Su Dolu Konserve Kutusuna Balıklama Atlamak adlı oyununda adı geçen gösteriyle meşhur olan Soytarı Pierre'in aslında hiç bir hüneri olmayan bir insanken, aşkın verdiği güç ve inançla numarasını yapmaya karar vermesi anlatılır.

Metin Balay, özellikle AST için yazdığı oyunlarla tanınan bir rejisör/akademisyendir. Yazdığ oyunlar Türkiye'de insan olma izleği üzerine temellendirilmiştir. İnadına İnsan bunun en başarılı örneklerinden birisidir. Dil, din, ırk, milliyet farkı olmadan insanın sevinçte ve kederde ne kadar ortak yönleri olduğunu anlatan 6 öyküden oluşmuştur. İnadına Yaşamak da insanın sorunlar karşısında ayakta kalabilme, başa çıkabilme gücünü gösteren beş öyküden oluşan bir oyundur. Son derece 
başarılı bir Tartuffe uyarlaması olan $\underline{\text { Yobaz' }}$ da adres göstere göstere, kıvrak bir dille, Moliere'den fedakarlık etmeden yapılan bir Türkleştirmeyle, irtica ve sahte din simsarlığ Deniz Diye Bir Delikanlı' da Deniz Gezmiş ve arkadaşlarının trajik yaşamlarını anlatır.

Nesrin Kazankaya, oyunculuk ve yönetmenlik deneyimini oyun yazımına aktaran bir sanatçıdır. Tiyatro Pera için yazıp yönettiği oyunlar son dönemde oldukça dikkat çekmiştir. Bu oyunların hepsinde toplumsal ve siyasal bir derdin varlığı hissedilmektedir. $\mathrm{Bu}$ oyunlar şunlardır: Bosna savaşının insanlar üzerindeki travmatik etkisinin işlendiği Dobrinja' da Düğün, Lilian Hellman'ın Julia adlı öyküsünün uyarlandığı Seyir Defteri(Julia), Türkiye'nin çok partili döneme geçişinin ve 70’lerdeki siyasi dönüşümü Nişantaş11ı bir ailenin iki kuşağı üzerinden anlatıldığı Şerefe Hatıralar , 80 darbesinin bir profesör ve hulahup oynayan bir kızın gözlerinden aktarıldığ Profesör ve Hulahup . Kazankaya’nın oyunları, yabancılaşan aydın ve özel hayatlar izleğini, politik bir duruşla harmanlaması açısından oldukça ilginçtir.

Toygun Orbay , çok yönlü kişiliği içinde fazla eser vermemekle birlikte göze çarpan bir yazardır. Bir satranç oyunu metaforu üzerinde çağımızın aydınının varoluş sorunlarını işlediği Mat ve bir istasyonda tren beklerken yaşamlarını da sorgulayan bir kadın ve erkeğin bu kısa birlikteliklerini felsefi çağrışımlarla aktardığı 21.15 Treni, son yıllarda DT sahnelerinde sahnelenmiş oyunlarıdır.

Opla Zo'nun Dramı, Adamlar, Yangin Duası adlı avant-garde oyunlarıyla tanınan Berkun Oya; Türk edebiyatının klasikleşmiş eserleri olan Aşsk-1 Memnu, Kiralık Konak, Yııldız Olmak Kolay mı gibi romanları sahneye uyarlayan ve Argonotlar söylencesini aktaran Altın Post ve Menderes'in özel ilişkileri ve siyasi yaşamının insanca bir bakışla yorumlayan Yarım Bardak Su'nun yazarı Tarık Günersel; Konstantiniye'nin Güneși ile Bakırköy Oyun Yazma yarışmasında ödül alan ve mübadeleyi işlediği Sevgili Hayat ile adını duyuran Funda Özşener; 90'ların ikinci yarısından itibaren oyunları oynanmaya başlayan Mem ve Zin , Ateș Gelen, Çok Geç Olmadan ve Muhtaro'da Güneydoğu Anadolu yöresinin efsanelerini, kültürünü , çelişkilerini ve sosyopolitik sorunlarını konu edinen Cuma Boynukara; 1980'lerde başladığı oyun yazma serüvenini pek çok oyun yazma yarışmasında aldığ1 ödülle sağlamlaştıran ve Kaşif-i Eyvah Nadir Efendi adlı meddah oyununu, kültürü bahane ederek insanları soyan bir çetenin anlatıldığı Kültürevi’ni yazan Ahmet Önel, Altıdan Sonra Tiyatro'da yazdığg 1 oyunlarda rol de alan ve bekleme salonunda karşılaşıp, karşılarına çıkan bir engel neticesinde beklemekten vazgeçen üç kişinin şiddet ve bilmeceyle örtülü çatışması üzerine kurulan Bekleme Salonu'nun, yılın en iyi yazarı almasına neden olan, psikodrama yöntemiyle dört kadının kişiliklerinin ve hedeflerinin değiştirilme sürecini oldukça eğlenceli bir dille anlatan politik komplo teorisi O.B.E.B.(Ortak Bölenlerin En Büyügü̈)' in yazarı Yiğit Sertdemir de bu dönemde yavaş yavaş adlarını duyurmaya başlayan yazarlar olarak sayılabilirler.

Sonuç olarak yazarlar bağlamında son on yıl içinde tiyatro repertuvarlarına göz atıldığında, Turgut Özakman, Güngör Dilmen, Haldun Taner, Orhan Asena, Vasıf Öngören, Melih Cevdet Anday, Nazım Hikmet, Recep Bilginer, Tarık Buğra, Aziz Nesin gibi pek çoğu Türk tiyatrosunun altın çağı olan 1960'larda ürünlerini vermeye başlamış yazarların oyunlarının hala oldukça popüler olduğunu 
görüyoruz. Ödenekli tiyatrolar özellikle edebiyat uyarlamalarına rağbet göstermekte, Reşat Nuri Güntekin, Ahmet Hamdi Tanpınar, Hüseyin Rahmi Gürpınar, Ayla Kutlu, Aziz Nesin, gibi Türk roman yazarlarının romanlarından ya da Nazım Hikmet, Edip Cansever gibi şairlerden şiir uyarlamalarını artık gittikçe okumaktan uzaklaşmış olan Türk halkına sahne vasıtasıyla ulaştırmayı bir görev edinmektedirler. Ancak sahnelenen yerli oyunlar içinde yeni yazarlara, yeni oyunlara ve yeni arayışlara yer verme oranının pek de teşvik edici olduğu söylenemez. DT’nin son yıllarda getirdiği \%70 yerli oyun oynanması temayülü bile, yazılan yeni oyunların sıradanlık ölçülerini nadiren aşabilmesi nedeniyle zorluklarla uygulanmaktadır. 2009'da 60. Yılını kutlayacak DT'nin 60 yılını temsilen, hiç oynanmamış 60 yerli oyun oynama projesi, tam da bu nedenden ötürü gerçekleştirilmesi oldukça meşakkatli bir misyona dönüşmüştür. Bilindiği gibi izleyici, karşısına çıkacak ürünün niteliğiyle ilgilenir. Yerli yazarları teşvik etmek için sahnelenen zaaflı oyunlar, zaten başlı başına bir sorun oluşturan izleyici oranlarında düşüşe sebep olmaktadır. Bu da riskli oyunların izleyici ile buluşması olasılığını azaltmaktadır. Oysa bu durum tam da bir kısır döngünün yansımasıdır. Oyunu sahnelenmedikçe hiçbir oyun yazarı yeterince olgunlaşacak motivasyonu gösteremez. Oynanmayan oyunların yazarı olmayı kimse istemez. Ve her oynanmayan oyun, o yazarın -eğer çok idealist değilseyeni bir oyun yazma isteğini ve gücünü tahrip eder. Ancak sahnelenen her kötü oyun da, zaten zorla gelen izleyicinin kaçmasına neden olur. Tiyatro sanatının etkisini ve prestijini azaltır. Bu durum Türk tiyatrosunda ciddi bir travmaya neden olmaktadır.

\section{Tür ve Temalara Göre Oyunlar}

Son 10 yıllık dönemde sahnelenen oyunları tematik olarak inceleyecek olursak, şöyle bir resim ç1kmaktadır:

2000'li yılların yetiştirdiği oyun yazarlarının ve sahnelenme şansı olan oyunların pek çoğunun 1980’lerin mirasını taşıdığı görülmektedir. Yazılan oyunları tematik olarak ayırdığımızda, hala yabancılaşmış bireyin kendini sorgulamasının, kadın erkek ilişkilerinin ve domestik komedilerin en popüler konu dağarcığını oluşturduğu söylenebilir. Dini ve tarihi kişiler ya da olaylar, yoğun olmasa da yazarlarca tercih edilen konulardır. Edebiyat uyarlamaları en çok rağbet edilen oyunlar arasında yer almaya başlamıştır. Artık köy ya da gecekondu gerçeği üzerine yazılan ya da bütünleşememiş kent nüfusunun sorunlarını işleyen oyunlar yok denecek kadar az yazılmaya başlanmıştır. Cumhuriyet'in ilk yıllarından beri popüler bir konu olan aile, başka bir yönelime kaymış, eksene kadın-erkek ilişkisini koyan, modern toplumda parçalanan birliktelikleri ya da aydın bireylerin her şeye karşın beraber olabilme şartlarının sorguladığı oyunlara bırakmıştır. Bu noktadan bakıldığında aile kurumu, çekirdek ailenin de temeli olan kadın-erkeğe indirgenmiş, komediler dışında, çocuklar ile olan ilişkiler büyük ölçüde dışlanmıştır. Geniş ailenin diğer fertleri de yine komediler dışında, aynı kaderi paylaşmışlardır. Kadının birey olma mücadelesi ya da daha geniş anlamıyla kadın sorunları da "feminist tiyatro" yazan (Zeynep Kaçar gibi) birkaç yazar ve grup dışında popülerliğini kaybetmiş konulardır. Sınıf çatışması da yazarlarımızın ilgi alanının dışına çıkmış, bunun yerine popülist “yeni dünya düzeni” eleştirileri 
tercih edilmeye başlanmıştır. Sayısı çok fazla olmasa da geleneksel Türk tiyatrosunun meddah, ortaoyunu ve köy seyirlik geleneğini kullanan göstermeci oyunları, yazarların elinde yeniden şekillenmekte, çağdaş konuları geleneksel formlarla kaynaştırarak aktarmaya çalışılmaktadır, ama bunlar da yeni bir biçim, form denemesine girişmekten uzaktırlar ve denenmiş kalıpları kullanmaktadırlar. Bir başka yönelim de yazılmaya başlayan fantastik-absürd içerikli oyunlardaki artıştır. Birkaçı hariç, toplumsal duyarlılığa sahip yazarların pek çoğu, toplumsal-siyasal konulardaki düşüncelerini daha dolaylı üsluplar seçerek anlatma yolunu tutturmuşlardır. Artık kişi, olay ve durumlar Türkiye'nin belli bir bölgesinde belli kişiler üzerinden kurgulanmaktansa, dünyanın belirsiz bir yerinde, genel ya da absürd isimler almış kahramanlar üzerinden aktarılmaktadır. Böylece faşizm, işkence, diktatörlük, darbe gibi konular görünüşte daha evrensel, ama daha çekingen bir üsluba oturmakta, hatta Mrozeck tarzı bir absürd izleğin benimsendiği görünmektedir. Coşkun Irmak'ın 12 Eylül'le hesaplaşma süreci üzerine gidilen oyunları gibi doğrudan toplumsal eleştiri yapılan oyunlar yazılmakla birlikte tiyatrolar henüz bu tür oyunlara repertuvarlarında pek yer vermemektedirler. AB ilişkileri üzerine birkaç oyun yazılmıştır, ancak sahnelenme şansına sadece Özcan Özer'in Avrupa Komedyası sahip olmuştur. Globalizasyon, postmodernite, suç, öteki olma, savaş, tek kutuplu dünya düzeni, çok kimliklilik, terör, teknoloji, etnisite, radikal İslam'ın ve faşizmin yükselişi, hızlı değişim, sınıfsal ve ideolojik referansların kaybedilmesi gibi günümüze damgasını vuran sorun ve olgular oyun yazımı ve sahnelenmesinde pek ilgi görmemektedir. Bu da ne yazık ki tiyatronun dünyayı, ülkeyi ve gündemi roman ve sinema gibi sanat dallarının arkasında kalarak takip ettiği imajını doğurmaktadır.

12 Eylül ve ardından yaşanan yeni dünya düzeninin aydın ve sanatçılar üzerinde ciddi bir travma yarattığı açıktır. Üstelik bu dönem dünyada postmodernizmin tüm şiddetiyle yaşandığı yıllara tekabül etmektedir. Yalnız ülkemizde değil, tüm dünyada politik bakış açısının ve onunla bağlantılı bir sanat formu olan toplumcu gerçekçiliğin ciddi bir düşüşe geçtiği gözlemlenmektedir. Artık birey toplumsal ideallerin değil, yakın çevresindeki gündelik sorunların üzerine daha çok odaklanmaktadır. Aile kavramının uğradığı erozyon da göz önüne alınacak olursa, kadın-erkek ilişkisi ve çevresine yabancılaşan okumuş, aydın birey, özellikle oyun yazarlarının algısı içinde odağı oluşturmaktadır. 2000’li yılların Türkiye tarihine AKP yılları olarak geçtiği de düşünülecek olursa, aydınların kendilerini her geçen gün biraz daha yalnız hissetmeleri anlaşılabilir. Ayrıca son zamanlarda AKP'nin ödenekli tiyatroların repertuvarlarına yaptığı siyasi müdahaleler de sansür sorununu gündeme getirmektedir. Ancak tüm bu uzaklaşmalar içinde, tiyatro da yavaş yavaş hayattan ve toplumdan kopuk bir sanata doğru dönüşmeye başlamıştır. Zaten tiyatronun yerini tutacak boş zaman alternatifleri büyük bir patlama yaşamaktadır. Memlekette sanatı destekleyen bir eğitim ve kültür politikasından söz etmek güç olduğu için de tiyatro izleyicisini uzun vadede artırmaya yönelik girişimler çok sınırlı düzeyde kalmaktadır. Geleceğin izleyicileri genç ve çocuklara yönelik eğitim departmanları, ödenekli tiyatrolarda bile bulunmamaktadır. Ülkemizde tiyatro üretiminin alt yap1 sorunlarından, rejisör azlığına kadar pek çok zaafı bulunmaktadır. Ama unutulmaması gereken en önemli nokta, bir ülkede tiyatroyu halka mal eden ve kalıcı olan aracın, tiyatro yazını olduğu gerçeğidir. 


\section{Sonuç}

2000'li yılları tiyatro yazınımızın nitelik ve nicelik açısından hala tökezlediği yıllar olarak adlandırmak mümkündür. Yazılan oyunların pek çoğunun sadece günü değil, çağı da etkileyecek, zamanın süzgecinden geçip gerçekten Türk tiyatrosunun önemli yapı taşlarını oluşturacak nitelikte olduğu söylenemez. 12 Eylül travması atlatılmış gözükse de, tiyatronun canlanmasını sağlayacak ateşleyici gücün eksik olduğunu söylemek için pek çok sebep ileri sürülebilir. Ancak, tiyatro alanında güçlü bir yazın geleneği oturmadıkça, ortaya çıkan oyunlar da izleyici kazanmak için pek olumlu bir katk1 sağlamayacaktır. Bu durumun nasıl çözülebileceğine, dizi ve reklam piyasasına kayan yazarların tiyatro alanında nasıl yetkin ürünler vereceğine dair bir strateji geliştirilmesi gerektiği açıktır. Oyun yazma yarışmaları, tiyatro yazarlığının gelişmesinde teşvik edici bir role sahip olmakla birlikte, dereceye giren eserler sahnelenmediği takdirde, somut, pratik bir sonuç yarattı̆̆ını söylemek güçtür. Bu nedenle hem eğitmeye, hem de sahnelemeye yönelik bir model üzerinden gidilmesi faydalı olabilir: Mehmet Ergen'in British Council işbirliği ile yürüttüğü Oyun Yaz atölyeleri yazar yetiştirilmesinde ya da yazarlar ile tiyatro insanlarının buluşturulmasında son derece yararlı bir modeldir. Geçtiğimiz yıl ilk ürünlerini veren bu atölye ilk oyunlarını yazacak adaylardan, kalem, kağıt ve gazete getirmelerini isteyerek işe başlamıştır. Proje, süreç içinde yerli, yabancı yazar, dramaturg ve rejisörlerle işbirliğine giderek, yazar adaylarının fikirlerinin oyun haline getirilmesini sağlamaktadır. Yerli ve yabancı oyun yazarları içinde nitelik ölçütünü ele aldığımızda, tiyatro ya da oyunculuk kökenli olanların oldukça önemli bir oran tuttuğu gözlemlenmektedir. Bu başarıda, söz konusu yazarların sahnenin yapısını ve zaaflarını iyi bilmelerinin önemli bir faktör olduğu yadsınamaz. Sahneye hakim tiyatro profesyonellerinin desteğinin, yeni oyun yazarlarının yetişmesinde katkı sağlayacağı açıktır. Benzer bir model, ödenekli tiyatrolar bünyesinde de gerçekleştirilebilir. Bilindiği gibi ödenekli tiyatroların misyonlarından birisi, tiyatronun memleket çapında yaygınlaştırılmasını sağlamak ve yeni yazar yetiştirilmesine katkıda bulunmaktır. Ödenekli tiyatrolara gönderilen metinler içinde umut vaat edenlerin seçilerek, yazarlarıyla düzenlenecek bir dizi atölye çalışması yapılması, yazılan oyunların niteliklerini yükseltecek, sahnelenebilecek seviyeye getirecektir. Uzun vadede bu çalışma yeni bir yazar kuşağı yetiştirilmesi adına çok anlamlı sonuçlar verecektir. Bu şekilde oluşturulacak stratejiler orta ve uzun vadede uygulandığı takdirde, Türk tiyatrosunda yeni yazar yetişmesi, yazılan oyunların niteliğinin yükselmesi ve tiyatrolar tarafından sahnelenebilecek bir düzey göstermesi mümkün olacaktır.

\section{Kaynaklar}

Akı, N.(1968). Çağdaş Türk Tiyatrosuna Toplu Bakış. Ankara: Bilgi Basımevi.

Akınc1, U. (2003). Kalemden Sahneye, I. İzmir: YGS yayınları.

And, M. (1983). Cumhuriyet Dönemi Türk Tiyatrosu. Ankara: Türkiye İş Bankası yayınları.

Belkıs, Ö. (2003). Kalemden Sahneye II. İzmir: YGS yayınları. 
Çelenk, S. (2003). Kalemden Sahneye III. İzmir: YGS yayınları.

Korad Birkiye, S. (1996). "Representation of Family and Women in Turkish Republican Drama". Unpublished MS dissertation, Ankara: METU.

Nutku, Ö. (1985) Dünya Tiyatrosu Tarihi 2. İstanbul: Remzi Kitabevi. 


\title{
Summary
}

\section{Turkish Playwrighting in the New Millenium}

\author{
Selen KORAD BİRKIYY* \\ İstanbul Devlet Tiyatrosu
}

As a living art form, theatre reflects the spirit of its epoch. Turkish theatre can be defined as an arena of changing perspectives, ideologies and mentalities. Previous researches (Ak1, 1968; And, 1983; Nutku 1985; Sav, 1984; Akınc1, 2003; Belkıs, 2003; Çelenk, 2003; Korad Birkiye, 1996) show this tendency until late 1990s. In these researches, relationship between theatre and socioeconomic transformations in Turkish Republican era are shown. In this process 1980 had a peculiar status comparing with the previous periods of the Republic. After 1980 military intervention, Turkish theatre lost its acceleration, totally. Although the negative influence of the intervention on intellectuals and artists is subject of another paper, apoliticalisation process and the stagnation of playwrighting is the focus of this research. After 20 years from the military intervention, world as well as Turkey is directed to a very different route. We met with neo-liberalism, postmodernism, spare time alternatives, loosing of ideologies, rising of fundamentalism and one-polar world. In these new conditions, it can be presumed that, the playwrighting should be very sensitive to the changing world. But the truth is totally different in Turkey.

There are several objectives of this study: First objective is determining the repertory policies of theatres in terms of giving chances to the new playwrights and their plays; secondly, determining the generation of new playwrights, their themes and styles of their plays; thirdly, trying to propose some solutions to the problems of playwrighting in Turkey.

\section{Methodology}

The aim of this research is to evaluate the situation of playwrighting in Turkey in the new millennium. So the research question is "how can we define the direction of Turkish theatre in the last decade?" In order to do this, repertoires of some subsidized and private theatre companies was investigated. This research will show the situation of the theatre and the playwrighting in Turkey. The research will be a descriptive one, primary and secondary data will be collected and a content analysis will be made on the new plays in terms of the themes and styles. So related to the researches about the previous phases of Turkish theatre, the portrait of Republican Turkish drama will be updated.

It is assumed that a written script will be a complete theatre piece when it meets with the audience on the stage. So only the plays which have been staged by professional theatres will be taken into account in this study. By using judgmental sampling, the repertoires of professional theatres are studied. And,

*Dr.,Dramaturg, İstanbul Devlet Tiyatrosu, Eposta: koradbirkiye@yahoo.com 
mainstream theatres which are doing regular productions in the last 10 years have been selected. So repertoires of 21 theatres were investigated. This means that over 1500 plays were studied and it was assumed that, this sample was representing the tendency of the whole population.

\section{Limitations}

Scripts which are accepted by literary committees of subsided theaters, published plays, children plays are not considered, unless they're staged. In addition, avant-garde, semi-professional, amateur, and university theatres as well as stand up theatres are excluded.

\section{Frequency of the New Playwrights/Plays on the Repertoires of Theatres}

We can divide these theatres into two: subsidized and private theatre companies.

a) Subsidized Theatres: State Theatre has the largest audience share all over Turkey. It is the largest theatre institution which composed of more than 2000 artists, technicians and office staff in 13 cities with 29 venues. Between 1999-2008 the average number of the productions per year was 122. The half of the plays is domestic and the rest was foreign plays. But average number of new plays and playwrights in the repertoire was only 7 per year. On the other hand, staging new plays of domestic playwrights differs from one city to another. For instance proportion of the new domestic plays was highest in Istanbul State Theater. There are two reasons of this difference: Firstly, in the metropolitan areas competition among theatres as well as all kinds of spare time activities are high, and secondly, Istanbul State Theatre prefers to enter the market by using niche strategy. On the other hand, in the small cities, repertoires of State Theaters are composed of classical domestic plays.

Istanbul Municipality Theatre is the 2nd biggest theatre organization in Turkey. Average 11 new plays staged in every season, and the proportion of domestic plays to foreign plays differs from season to season. In 10 years period the total number of the new plays -excluding the adaptations- was only 6. In the same period, the total number of the productions was 109.

In Bakirköy Municipality Theatre only 1 new play of a new playwright was staged in its history. In Kocaeli Municipality Theater, 2 of total 43 plays were the new plays. In Eskisehir Municipality Theater, 7 of total 37 productions were the new ones. But these new plays were mostly comedies and musicals. Hence it could be concluded that, these 3 theatres prefers productions and playwrights without taking any risk.

b) Private Theatres: Tiyatro İstanbul, Tiyatro Kare, Oyun Atölyesi, Tiyatro Kedi and Aksanat Prodüksiyon Tiyatrosu composes their repertoires hardly with new domestic plays and playwrights. So in 10 years period, number of such plays was 1 or 2. Tiyatro Stüdyosu didn’t put any domestic plays in its repertoire. Tiyatro Oyunevi, Tiyatro Pera, Semaver Kumpanya gives more chance to the new playwrights. On the other hand, Sadri Alışık Tiyatrosu changes 
its repertoire choices from serious new domestic plays to the new boulevard comedies. Tiyatro Ayna is staging domestic plays which were written for their company and their star. Kent Oyuncuları was choosing new domestic plays only for one man/woman plays in the last decade, although they did a lot of domestic plays in their history. Dostlar Tiyatrosu and Ankara Sanat Tiyatrosu try to follow the political agenda of the country by staging adaptations or new plays. Ankara Ekin Tiyatrosu usually prefered to make productions written by their own playwrights.

\section{The Mostly Staged Playwrights}

In the last 10 years writers of mostly staged new domestic plays are as follows:

Refik Erduran, Tuncer Cücenoğlu, Behiç Ak, Özen Yula, Turgay Nar, Civan Canova, Raşit Çelikezer, Hasan Öztürk, Coşkun Irmak, Metin Balay, Nesrin Kazankaya, Toygun Orbay, Berkun Oya, Tarık Günersel, Funda Özşener, Cuma Boynukara, Ahmet Önel and Yiğit Sertdemir.

When we study the repertoires of theatres in the last 10 years, we see that playwrights who begin to write in 1950s and 1960s such as Turgut Özakman, Güngör Dilmen, Haldun Taner, Orhan Asena, Vasıf Öngören, Melih Cevdet Anday, Nazım Hikmet, Recep Bilginer, Tarık Buğra, Aziz Nesin are still very popular. Subsidized theatres prefer literature adaptations to a great extent. But neither of the theatres encourages new playwrights and their plays at all. Even the $\% 70$ domestic plays principle in the repertoire selection of State Theater can't be realized because of several practical reasons.

In sum, the picture of the situation of the new plays and authors of the new millennium, is quite pessimistic. There are very few authors whose plays have been staged by the theatres. The theatre companies usually prefer plays of experienced authors who have been writing for 20-40 years. Mostly staged plays of the new playwrights are always the same. Such a situation doesn't give any motivation to new authors. Hence, it could be said that, the total number of foreign plays are more than domestic plays in the repertoires of theatres as a whole and the percentage of the new ones among domestic writers is quite low.

\section{Themes of the New Plays}

The new playwrights and their plays in the new millennium are mostly carrying the inheritance of the 1980's. Alienation of the individual and his self-questioning, light comedies, intimate, personal relationships between sexes, historical figures or legends, absurd plays and literature adaptations are usually popular themes among the new Turkish playwrights. On the other hand, country or shanty town plays or the problems of people who can't integrate into town culture are neglected subjects. The 
very popular subject of the Republican period, the family relations directed to another route. Now the axis is not the nuclear or extended family itself, but the relationship between man and woman.

\section{Conclusion}

EU relations, war, terror, technology, otherness, fundamentalism, rapid social change, loosing of references, crime, social problems are not popular themes among new playwrights. Most of the themes are alienated from the social reality of the country and the world. The individual andthe personal problems are the most important focus which means that authors are losing the connection of social, political or cultural references behind the actions. On the other hand, most of the political or social plays are losing the personal level while trying to impose the didactic messages. Politics is usually subject of comedies or fantastic plays. So, theatre is losing its respect, influence and audiences in Turkey. And the solution may be training of the new playwrights by organizing series of workshops, raising staging facilities and educating youngsters who are the future audiences of theatre. 